\title{
Comparison of finite element results with photoelastic stress analysis around dental implants with different threads
}

\section{Porównanie wyników metody elementów skończonych w ocenie naprężeń fotoelastycznych wokół wszczepów zębowych o różnym gwincie}

\author{
Maryam Geramizadeh",B-D, Hamidreza Katooziann ${ }^{1, E, F}$, Reza Amid ${ }^{2, A, F}$, Mahdi Kadkhodazadeh²,A,E,F \\ 'Department of Biomechanical Engineering, Amirkabir University, Tehran, Iran \\ ${ }^{2}$ Dental Research Center, Research Institute of Dental Sciences, Dental School, Shahid Beheshti University of Medical Sciences, Tehran, Iran \\ A - research concept and design; $B$ - collection and/or assembly of data; $C$ - data analysis and interpretation; \\ $D$ - writing the article; $E$ - critical revision of the article; $F$ - final approval of the article
}

Address for correspondence

Mahdi Kadkhodazadeh

E-mail: Kadkhodazadehmahdi@yahoo.com

Funding sources

None declared

Conflict of interest

None declared

Received on November 29, 2017

Reviewed on February 2, 2018

Accepted on February 6, 2018
DOI

10.17219/dmp/85077

Copyright

○ 2018 by Wroclaw Medical University

and Polish Dental Society

This is an article distributed under the terms of the

Creative Commons Attribution Non-Commercial License

(http://creativecommons.org/licenses/by-nc-nd/4.0/)

\begin{abstract}
Background. The finite element method (FEM) has been used to analyze stress and strain distributions around 3 suggested dental implants with newly-designed thread parameters and the optimal shape of the implant was introduced considering the response surface optimization method sensitivity analysis. Experimental tests seemed necessary to confirm the results of the FEM.
\end{abstract}

Objectives. The aim of this study was to use experimental tests to prove the results of a finite element analysis of 3 dental implants with different thread designs under axial loads. Photoelastic stress analysis was chosen due to the similarity of analysis with FEM.

Material and methods. Two-dimensional models of 3 dental implants were built of grade 4 titanium to be tested in the polariscope. Model 1: A tapered implant with V-shaped threads; Model 2: A tapered implant with micro-threads in the upper area and V-shaped threads in the rest of the body; Model 3: A tapered implant with reverse buttress threads in all areas. Axial loading of $100 \mathrm{~N}$ was applied to the top of the implants and stress patterns and the maximum stress were evaluated for each implant.

Results. The minimum Huber-Mises-Hencky stresses of cortical bone were recorded in model 2, a tapered implant with micro-threads in the upper area and $\mathrm{V}$-shaped threads in the rest of the body. The value for $100 \mathrm{~N}$ loading was $15.25 \mathrm{MPa}$, which was in agreement with the FEM.

Conclusions. Considering the stress patterns and values obtained from experimental tests of photoelasticity, the tapered implant with micro-threads in the upper area and V-shaped threads in the rest of the body has the most uniform and desirable stress distribution in the surrounding cortical bone and is preferred to be used in future applications.

Key words: dental implant, biomechanics, finite element, photoelasticity

Słowa kluczowe: implanty stomatologiczne, biomechanika, metoda elementów skończonych, fotoelastyczność 


\section{Introduction}

Engineering techniques used to evaluate strain-stress fields are useful tools in the study of biomechanical applications. These experimental and numerical engineering tools were imported to biomechanics, in particular in dental biomechanics, a few decades ago. Several experimental techniques have been used in dental biomechanics, like photoelasticity, ESPI (Electronic Speckle Pattern Interferometry), strain gages, and other kinds of transducers. Photoelasticity is an experimental technique used for stress analysis of different objects under various loading conditions. It relies on transparent materials that show fringes when load is applied. This effect is the result of refraction of the polarized light by internal deformations due to stresses occurring in the model. Interpretation of these fringes shows the stress distribution and allows the measurement of their direction and magnitude. In the photoelastic method, a model similar to the studied structure is made in transparent material that has photoelastic properties. This model is placed under loading of the work conditions, which results in a deformation and color patterns. ${ }^{1-3}$

Polariscope is an optical system that shows the establishment of the main stress directions, as well as the difference between the 2 components of main stress. It is made up of polarizer, analyzer, and wave plates. The polarized light crosses the wave plates and arrives at the observer as an image of the optic parameters. ${ }^{4,5}$

The study of photoelasticity in the specific area of dental implant systems is of great interest since it can be useful in analyzing the stress distribution in both abutments (different designs and types) and implants screws (different types and angulations). ${ }^{6}$

Zielak et al. used 8 different designs of implants from 2 manufacturers, which were connected to their abutments, placed into epoxy resin blocks and observed under a polariscope coupled to a universal testing machine while subjected to axial loads of $5 \mathrm{~N} .^{7}$ The obtained images were quantitatively analyzed by image analysis software. By this biomechanical study, it was possible to demonstrate a correlation of some implant characteristics to the colored fringe areas of tension distribution, a colorimetric method that can be used in comparative studies of photoelastic analysis. ${ }^{7}$

Udae et al. studied the photoelastic analysis of stress distribution on parallel and angled implants after installation of fixed prostheses. ${ }^{8}$ The purpose of this study was to compare stress distribution in the fixed prosthesis with 3 parallel implants, to the stress distribution in the same prosthesis in the existence of an angled central implant. The presence of applied tensions was observed in the models after applying the torque to retention screws. ${ }^{8}$

Goiato et al. has done a photoelastic stress analysis in prosthetic implants of different diameters: mini, narrow, standard or wide. 9 Six photoelastic models were fabricated in PL-2 resin as single crowns or splinted 3-unit piece. This experiment shows that under axial loading, the number of fringes is inversely proportional to the diameter of the implants in the single crown models. The author concluded that the standard implant diameter always gives better stress distribution than the narrow and mini diameter implants. Additionally, the splinted crowns show more uniform stress distribution. ${ }^{9}$

Geramizadeh et al. used the response surface optimization method (available in finite element software packages) to optimize the parameters of designed dental implants, including thread depth and pitch, in order to have a uniform and desirable stress distribution. ${ }^{10}$ In addition, the sensitivity of the simulation to different mechanical parameters was investigated and it was concluded that micro-thread parameters have greater effects on stress and strain values than the rest of the body's parameters.

Among the different aspects of design and analysis of dental implants, thread parameters are considered very important due to their effect on stress distribution. In the previous study, ${ }^{11} 3$ different dental implant designs were investigated using FE analysis, and model 2 was chosen as the best all around. In the present study, experimental tests were used to prove the former results and give better insight into the issue.

\section{Material and methods}

In our previous studies, modeling of the implants was done in Solidworks ${ }^{\circledR} 2014$ and imported to ANSYS $^{\circledR}$ Workbench software (ANSYS WB 2.0 Framework, v. 12.0.1, SAS IP ${ }^{\circledR}$, Cheyenne, USA). All screws had the same geometry in terms of length and diameter $(10.5 \mathrm{~mm}$ and $3.8 \mathrm{~mm}$ ) in order to focus exclusively on the effect of thread design. The implant neck was beveled with a $22^{\circ}$ angle relative to the vertical axis. This part had a $0.5 \mathrm{~mm}$ height and had to remain outside of bone. The area beneath the beveled margin had a $1 \mathrm{~mm}$ height with no threads and was to be placed in cortical bone. The rest of the body had specific thread designs as follows, to evaluate the effect of thread design on stress distribution: implant model 1 had V-shaped threads in the whole body; implant model 2 had $1.3 \mathrm{~mm}$ micro-threads on the upper part and the rest of the body was the same as model 1; implant model 3 had reversed buttress threads in all areas. The pitches of the V-shaped threads and micro-threads were 0.8 and $0.26 \mathrm{~mm}$, respectively. The reversed buttress thread had a $0.8 \mathrm{~mm}$ pitch as well. The implant bodies had an $8^{\circ}$ taper. A fixed rigid abutment with a $5 \mathrm{~mm}$ height was placed on top of the screw, where the force was applied. A bone block, $17 \mathrm{~mm}$ high and $12 \mathrm{~mm}$ wide, was built around the imported implants representing the surrounding bone in the second premolar region. A core of cancellous bone was covered with a thick layer of cortical bone with a constant width of $2 \mathrm{~mm}$. The 3 models are shown in Fig. 1. Also, the whole model is shown in Fig. 2. Static loading 

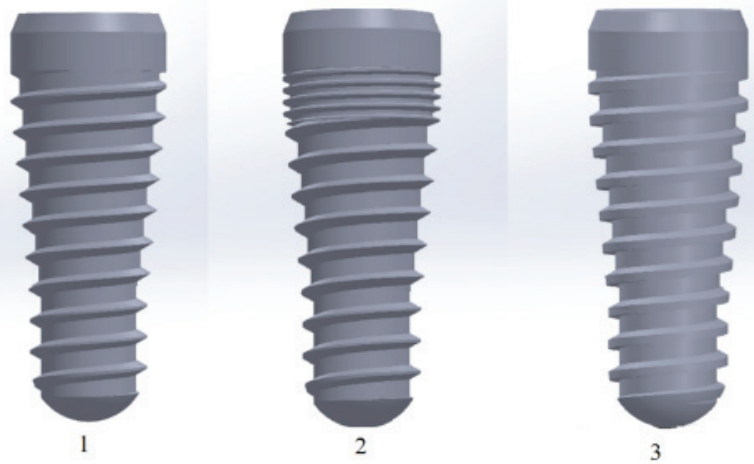

Fig. 1. Implant models with (1) V-shaped threads, (2) micro-threads and $\checkmark$-shaped threads, and (3) reversed buttress threads ${ }^{11}$

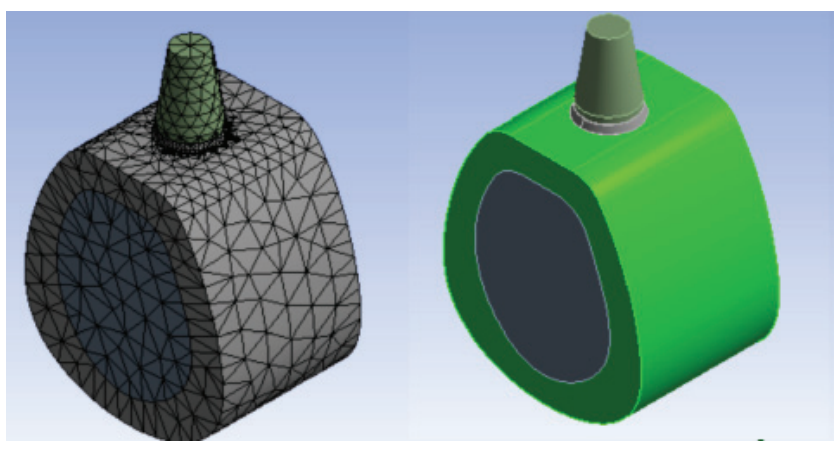

Fig. 2. Whole model including the implant and cortical, and cancellous bones

involved application of $100 \mathrm{~N}$ force at 0 and $25^{\circ}$ angles relative to the vertical axis. The implants were considered to be made of grade 4 titanium. The behaviors of the materials were represented with linear isotropic material models. The mechanical properties of the materials used in this study are shown in Table 1 . All materials were assumed to be homogenous, isotropic, and linearly elastic. ${ }^{11,12}$

In a plane stress problem, the thickness of the prototype is small in relation to the other dimensions; therefore, it can be assumed to function as a two-dimensional model. The 3 models of designed dental implants were built using a wire cut method (Fig. 3). Recently, these models were analyzed by means of the FEM and in this study the experimental tests were performed to prove the obtained results. ${ }^{11,12}$ The prototypes were placed in a box with small depth compared to the other dimensions, so it can be considered a 2-dimensional model. This box was filled with photoelastic material, which was a combination of EPL 215 (epoxy oil) and EPH 5161 (hardener of epoxy oil). The mixture was liquid shaped at first and after mixing, it solidified in a few hours and the implant was fixed in it.

Table 1. Mechanical properties of materials

\begin{tabular}{|l|c|c|c|}
\hline \multicolumn{1}{|c|}{ Materials } & $\begin{array}{c}\text { Young's modulus } \\
{[\mathrm{MPa}]}\end{array}$ & Poisson's ratio & $\begin{array}{c}\text { Density } \\
{\left[\mathrm{gr} / \mathrm{cm}^{3}\right]}\end{array}$ \\
\hline Cortical bone & 13700 & 0.3 & 1.85 \\
Cancellous bone & 1370 & 0.3 & 0.9 \\
Grade 4 titanium & 103400 & 0.35 & 4.5 \\
\hline
\end{tabular}

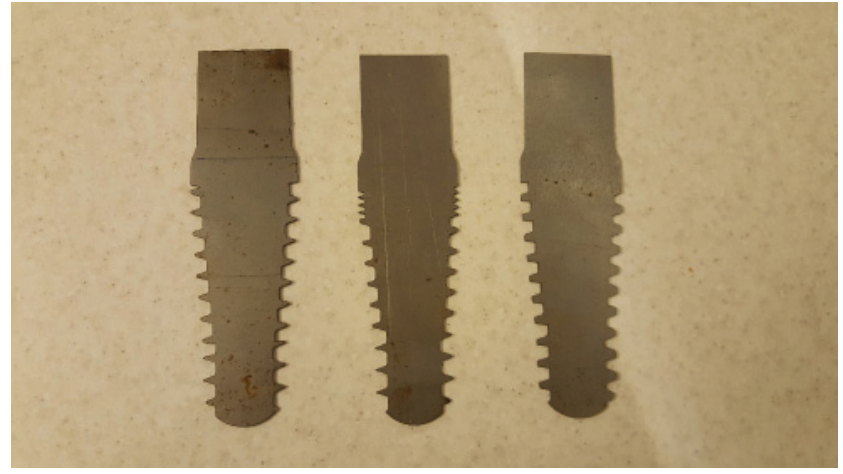

Fig. 3. Three models of dental implants with different thread designs
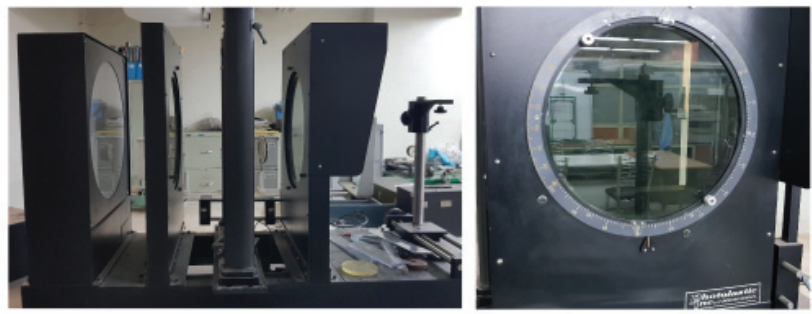

Fig. 4. Polariscope from 2 views

$100 \mathrm{~N}$ axial loading was chosen to be applied on the top of the implants, which results in stress distribution in the whole model. The maximum amount of stress in the surrounding material around the implant is of interest in this study, which can be calculated using the following procedure.

First, the polariscope, which is shown in Fig. 4, is calibrated and, to do so, a disc in compression with the same material as the photoelastic material used is placed in the system. The stress-optic equations employed in photoelasticity always include a sensitivity coefficient. This coefficient represents the proportional factor between fringe order and stress level, and its magnitude varies with the type of photoelastic plastic. Loads are applied diametrically across the disc thickness and, from the theory of elasticity, the stresses at the center of the disc are:

$\sigma_{1}=\frac{2 P}{\pi b d}, \quad \sigma_{1}=-\frac{6 P}{\pi b d}$,
$\sigma_{1}-\sigma_{2}=\frac{c}{b} \times N=\frac{8 P}{\pi b d} \quad \rightarrow \quad c=\frac{8 P}{\pi d N}$

Considering the color pattern, the center of the disk is green, which has 3.1 as $\mathrm{N}$ in the equation according to Table 1. Loading (P) of $3.5 \mathrm{~N}$ is applied and the prototype has a diameter $(\mathrm{d})$ of $9 \mathrm{~cm}$, which results in:

$c=\frac{8 P}{\pi d N}=\frac{8 \times 3.5}{\pi \times 0.09 \times 3.1}=31.85 \mathrm{~Pa} \times \mathrm{m}$

This parameter will be used to calculate the stresses in each point of the model. In order to calculate maximum stress in each model, the color pattern is considered in 2 ways: normal view and oblique view. $\alpha$ is the angle of the 2 views, which will be achieved using a prism light and, in this study, it is fixed at $30^{\circ}$ in all tests. 
The parameter of fringe order $(\mathrm{N})$ must be found in both views and finally the principle stresses can be calculated using the following equations. In these equations $\mathrm{N}_{\mathrm{n}}$ and $\mathrm{N}_{\mathrm{o}}$ are the fringe orders in normal and oblique views, respectively. The parameter $\mathrm{d}$ is the thickness of the model, which is $1 \mathrm{~mm}$ here. ${ }^{13,14}$

$\sigma_{1}=\frac{c}{d} \frac{1}{1-\cos ^{2} \alpha}\left(N_{o} \cos \alpha-N_{n} \cos ^{2} \alpha\right)$

$\sigma_{2}=\frac{c}{d} \frac{1}{1-\cos ^{2} \alpha}\left(N_{o} \cos \alpha-N_{n}\right)$

In FEM, the achieved stresses in the software are $\mathrm{Hu}$ ber-Mises-Hencky stress. Therefore, in order to compare the results, the principle stresses $\sigma_{1}$ and $\sigma_{2}$ must be converted to Huber-Mises-Hencky stress using this equation:

$\sigma_{\text {Von-Mises }}=\sqrt{\sigma_{1}^{2}-\sigma_{1} \sigma_{2}+\sigma_{2}^{2}}$

Therefore, in the next step, each prototype should be fixed in the system and the loading condition will be applied. The color pattern is photographed in the normal and oblique situation to be used in calculations of stresses.

\section{Results}

The maximum amounts of Huber-Mises-Hencky stress in each model were calculated using the above-mentioned equations. The distribution of colors in Fig. 5 for each implant was chosen using Table 2, which gives the fringe order in normal view. In addition, color orders in oblique views are found in Fig. 6, which will result in fringe orders of the oblique view from Table 1 . These parameters are used in equations 3 and 4 to calculate the principle stresses in each point. Equation 5 gives the Huber-MisesHencky stress, which makes it possible to compare the results with FEM. In this study, the maximum amounts of stresses are of great importance and examined carefully for each model. These values and the results of the FEM are reported in Table 3 to be compared easily.

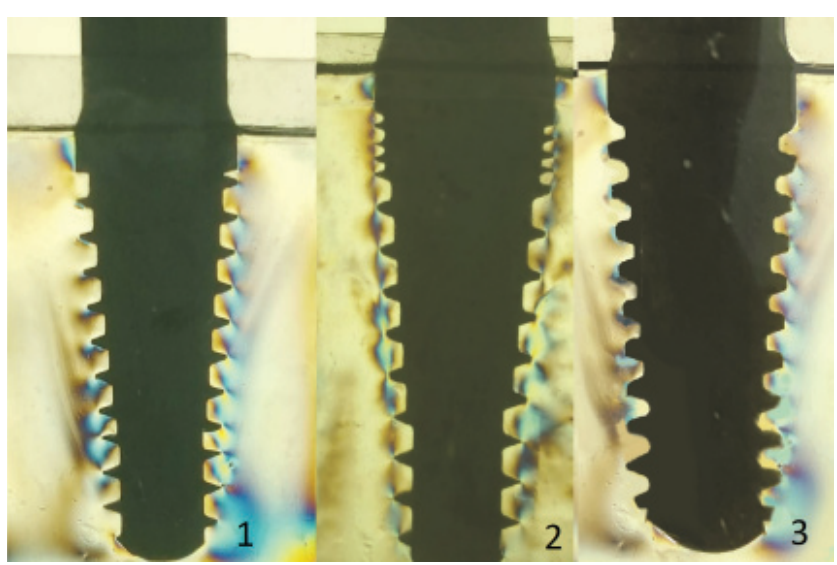

Fig. 5. Stress distribution in the models in normal view
Table 2. Fringe orders obtained from different color patterns

\begin{tabular}{|c|c|}
\hline Color & Fringe order \\
\hline Black & 0.00 \\
\hline Gray & 0.28 \\
\hline White & 0.45 \\
\hline Pale yellow & 0.60 \\
\hline Orange & 0.80 \\
\hline Dull red & 0.90 \\
\hline Purple & 1.00 \\
\hline Deep blue & 1.08 \\
\hline Blue-green & 1.22 \\
\hline Green-yellow & 1.39 \\
\hline Orange & 1.63 \\
\hline Rose red & 1.82 \\
\hline Purple & 2.00 \\
\hline Green & 2.35 \\
\hline Green-yellow & 2.50 \\
\hline Red & 2.65 \\
\hline Red/green transition & 3.00 \\
\hline Green & 3.10 \\
\hline Pink & 3.65 \\
\hline Pink/green transition & 4.00 \\
\hline Green & 4.15 \\
\hline
\end{tabular}

Table 3. Comparison of the results of FEM and photoelastic analysis

\begin{tabular}{|l|c|c|c|}
$\begin{array}{c}\text { Maximum Huber-Mises-Hencky } \\
\text { stress in cortical bone } \\
{\left[\begin{array}{c}\text { [MPa] } \\
\text { FEM }\end{array}\right.}\end{array}$ & Model 1 & Model 2 & Model 3 \\
Photoelasticity analysis & 17.9 & 17.77 & 18.7 \\
\hline
\end{tabular}

FEM - finite element method.

As can be seen, there is a negligible difference between the results of the FEM and experimental tests. Model 2, a tapered implant with micro-threads in the upper area and V-shaped threads in the rest of the body, had the lowest stress in critical points and seems to be safer.

Stress distribution in all 3 models in the normal and oblique views are shown in Fig. 5 and 6. Obviously, the most critical points in these pictures are the contact surface of threads and cortical bone. The first thread especially is the most important one since it has the biggest stress value.

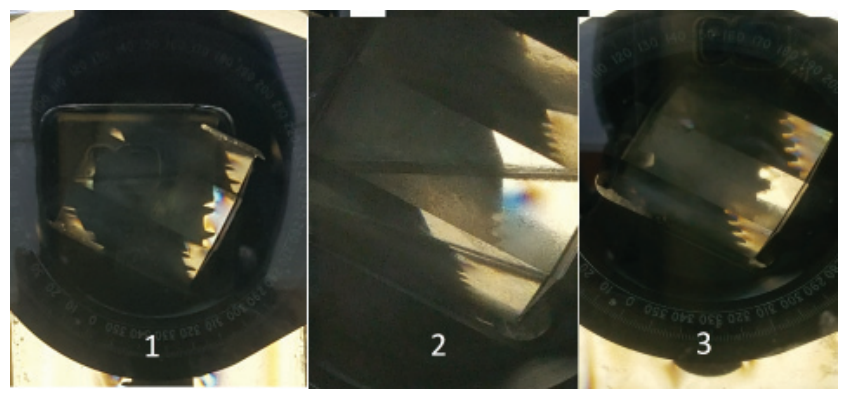

Fig. 6. Stress distribution in the models in oblique view 


\section{Discussion}

In this study, the maximum Huber-Mises-Hencky stresses in cortical bone were calculated using photoelastic stress analysis to be compared with the results of the FEM. The results are represented in Table 3, which shows enough agreement between these 2 methods. However, there is negligible difference between the stress patterns in the 2 methods, which can be acceptable due to the limitations of the experimental tests and assumptions made in the FEM. The experimental tests can represent results acceptably close to the real conditions. Therefore, they can be used to prove the results of the software analysis.

As can be seen in Fig. 5, the maximum stress is happening in the neck of the implant, almost in the first thread that has contact with the bone. Therefore, this area has the biggest risk of failure and the danger of overstressing in the surrounding cortical bone should be considered especially in this area. This was also the case in the FEM, so the design of the threads in the upper area is of great importance in the design and analysis of dental implants. ${ }^{15}$ Additionally, modeling the exact geometry of the implant complex, including the thread details, is essential for this setting. ${ }^{16}$ In the present analysis, all implants had the same taper and bevel angles, which enabled accurate comparison of the effects of thread design. They were built using cut wire that has an acceptable accuracy in this case.

As seen in Table 3 and Fig. 5 and 6, implant model 2 caused lower stress in cortical bone and the most homogenous stress distribution, which made it the best option amongst all, during the insertion procedure as well as during the loading of implants. This model had micro-threads in the neck, which helped reduce the stress values in cortical bone. It also had V-shaped threads, which are stronger for cutting the jawbone during the procedure of screw placement. This result was also found in previous FEM, and the experimental tests show great agreement with them. ${ }^{11,12}$

Ideal function of dental implants in the human body depends on the ranges of the stress and strain in the surrounding bone. These values should be within an optimal range. Exceeding this range might result in degeneration and fraction of the bone, and bone atrophy might occur in the case of stress values which are too low. ${ }^{17}$

There are some limitations and simplifications in this study. The polariscope used was only working in 2 dimensions. The $3^{\text {rd }}$ dimension, the thickness of the implant, was reduced to $1 \mathrm{~mm}$ and stress distribution is neglected in this dimension. This is obviously not the case in reality but it can be considered reasonable due to the similarity of the model in all directions. In addition, the only type of loading in this device is axial loading; therefore, other kinds of tensions such as shear stress cannot be analyzed. Another important factor is the assumption of isotropic and homogenous materials, which is not the case in the human body and may be responsible for the differences in results compared to other studies. Moreover, the absence of some components such as crown, which was not included in the model, may cause different effects on stress/strain patterns. However, these assumptions are acceptable in experimental tests and the results show reasonable agreement with FEM results. Future studies may focus on 3-dimensional photoelastic analysis of dental implants, which is a more realistic test, and of course a much more complex situation. In that case, shear stresses can be included in the loading conditions, which makes the analysis closer to reality.

In this study, it is concluded that a tapered implant with micro-threads in the upper area and V-shaped threads in the rest of the body has the optimum shape for the most desirable stress distribution. These tests proved that this thread design is the best one for the purpose of uniform and optimal stress distribution and is suggested to be used in future applications.

\section{References}

1. Philips JW. Experimental Stress Analysis. Vol. 3. $2^{\text {nd }}$ ed. Urbana-Champaign, IL: University of Illinois Board of Trustees; 1998.

2. Carvalho L, Roriz P, Simões J, Frazão O. New trends in dental biomechanics with photonics technologies. App/ Sci. 2015;24:1350-1378.

3. Corrêa CB, Ribeiro AR, Reis JM, Vaz LG. Photoelasticity in dentistry: A literature review. RSBO Rev Sul-Bras Odontol. 2014;11:178-184.

4. Cloud GL. Optical Methods of Engineering Analysis. London, England: Cambridge University Press; 1988;2.

5. Durelli AJ. Introduction to Photo-Mechanics. Vol. 4. $2^{\text {nd }}$ ed. Englewood Cliffs, NJ: Prentice Hall; 1965.

6. Shinde SB, Hirmukhe SS, Dhatrak PN. Photoelastic stress analysis: A review. Paper presented at: $5^{\text {th }}$ National Conference RDME; 2016.

7. Zielak JC, Filietaz M, Archetti FB, et al. Colorimetric photoelastic analysis of tension distribution around dental implants. RSBO Rev Sul-Bras Odontol. 2013;10:318-325.

8. Udae C, Markarian RA, Sendik CL, Lagana DL. Photoelastic analysis of stress distribution on parallel and angled implants after installation of fixed prostheses. Braz Oral Res. 2004;18:45-52.

9. Goiato MC, Pesqueira AA, Dos Santos DM, Haddad MF, Moreno A. Photoelastic stress analysis in prosthetic implants of different diameters: Mini, narrow, standard or wide. J Clin Diagn Res. 2014;8:ZC86-90.

10. Geramizadeh M, Katoozian H, Amid R, Kadkhodazadeh M. Threedimensional optimization and sensitivity analysis of dental implants thread parameters using finite element analysis. J Korean Assoc Oral Maxillofac Surg. 2017;14;145-152.

11. Geramizadeh M, Katoozian H, Amid R, Kadkhodazadeh M. Static, dynamic and fatigue finite element analysis of dental implants with different thread designs. J Long Term EffMed Implants. 2016;26:347-355.

12. Geramizadeh M, Katoozian H, Amid R, Kadkhodazadeh M. Finite element analysis of dental implants with and without microthreads under static and dynamic loading. J Long Term Eff Med Implants. 2017;27:35-42.

13. Doyle JF, Phillips JW. Manual on Experimental Stress Analysis. Vol. 2. $5^{\text {th }}$ ed. Bethel, CT: Society for Experimental Mechanics; 1988.

14. Kozłowska B. Two-dimensional experimental elastic-plastic strain and stress analysis. J Theor Appl Mech. 2013;51:419-430.

15. Zarei I, Khajehpour S, Zahedinejad P. Assessing the effect of thread design on stress and strain distribution around dental implants, using three-dimensional finite element analysis. J Dent Biomater. 2016;3:233-240.

16. Holmgren EP, Seckinger RJ, Kilgren LM, Mante F. Evaluating parameters of osseointegrated dental implants using finite element analysis - a two-dimensional comparative study examining the effect of implant diameter, implant shape, and load direction. Oral Implantol. 1998;24:80-88.

17. Frost HM. Bone "mass" and the "mechanostat": A proposal. Anat Rec. 1987;219:1-9. 
